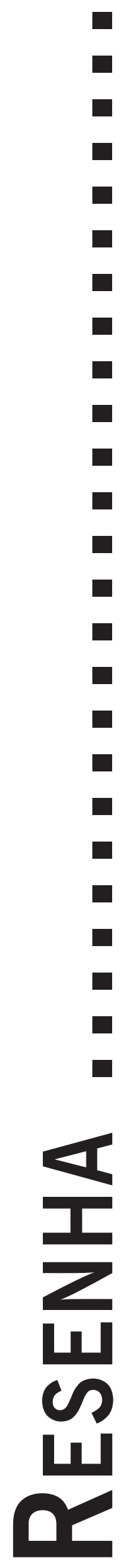




\title{
ELEMENTOS PARA UMA COMPREENSÃO DIAGNÓSTICA EM PSICOTERAPIA - O CICLO DO CONTATO E OS MODOS DE SER
}

\author{
(Ênio Brito Pinto, São Paulo: Summus, 2015)
}

\author{
Maria Paula Miranda Chaim \\ Pontifícia Universidade Católica de Goiás \\ Danilo Suassuna Martins Costa \\ Pontifícia Universidade Católica de Goiás
}

O livro recém-lançado em epígrafe - Elementos para uma compreensão diagnóstica em psicoterapia - o ciclo de contato e os modos de ser - é uma novidade nos estudos sobre o diagnóstico nas psicologias fenomenológicas, sendo fruto de muitos atendimentos terapêuticos em Gestalt-terapia e inúmeros estudos teóricos em psicologia do autor Ênio Brito Pinto. A publicação em questão proporciona uma compreensão diagnóstica com um olhar mais gestáltico sem negar, entretanto, a importância do Manual Diagnóstico e Estatístico de Transtornos Mentais (DSM).

O principal objetivo da obra é possibilitar um pensar em estilos de personalidade e em modos de ser que não necessariamente patológicos. Para cumprir com o intento, o livro tem como referencial os modos de ser e estilos de personalidade baseados no ciclo de contato, proposto pelo autor Ribeiro (2005), o qual o elaborou de forma clara e didática, tornando-o, portanto, fundamental para a compreensão diagnóstica fenomenológica em Gestalt-terapia.

A importância de se apontar para discussões e teorizações sobre a compreensão diagnóstica na abordagem gestáltica, se dá pela necessidade de não caracterizar um diagnóstico apenas como psicopatológico, mas psicológico, onde é considerado a totalidade do campo e a individualidade por meio do olhar fenomenológico e holístico, visando facilitar o desenvolvimento de potencialidades do cliente, características marcantes da Gestalt-terapia.

Ao apresentar uma nova compreensão diagnóstica, observa-se que esta é uma das atividades mais complexas e importantes a serem desempenhadas pelos profissionais no processo terapêutico. Logo, este livro se torna um instrumento referencial capaz de nortear a atitude terapêutica diante da demanda do cliente.

Indiscutivelmente, a compreensão diagnóstica em psicoterapia é um dos temas de grande interesse na atu- alidade e, como tal, sujeito à influencia de modismos. O livro, então, cumpre um papel importante de esclarecer dúvidas conceituais e oferecer informações relevantes para estudantes, profissionais da saúde, docentes e pesquisadores interessados no assunto. Para tanto, está organizado em 5 capítulos, de modo que consegue oferecer uma visão ampla da compreensão diagnóstica em Gestalt-terapia, considerando tanto os aspectos intrapsíquicos quanto os relacionais e com ênfase nos aspectos relativos à intersubjetividade.

O primeiro capítulo faz uma breve retrospectiva dos fundamentos da compreensão diagnóstica, onde a tese central é alertar sobre a importância de não reduzir a singularidade existencial e a história do cliente em um rótulo, julgando existir um padrão de normalidade. A forma de diagnóstico sugerida é aquela que parte do vivido do cliente, possibilitando perceber o homem em sua trajetória com suas potencialidades e limitações. A importância de partir do vivido corrobora com a visão fenomenológica de que nada substitui o estar com, e o entre - terapeuta-cliente. Portanto, a compreensão do diagnóstico acontece por meio do contato com o cliente e não apenas com o entendimento da semiologia. Em síntese, este capítulo aponta para uma perspectiva onde o diagnóstico não se esgota no sintoma, mesmo que este exponha o modo característico de ser ou o estilo de personalidade do cliente.

O capítulo 2 propõe-se a apresentar esta relação entre a compreensão diagnóstica e o estilo de personalidade. Inicia-se apresentando a composição do estilo da personalidade, que é estrutura e processo. Onde a estrutura permite a previsibilidade e o autoconhecimento; e o processo transmite a ideia de que a personalidade inova e se renova, oferecendo sempre possibilidades de mudanças, ou seja, modifica os aspectos da estrutura da personalidade. No momento em que entende os dois eixos da personalidade, inicia-se uma compreensão diagnóstica, pois 
a estrutura oferece uma tipologia, que possibilita o psicoterapeuta a se atender às tendências psicopatológicas e paradoxalmente o processo delega a ideia de que nenhuma tipologia, mesmo sendo um processo de redução, pode ser um reducionismo, já que cada pessoa precisa ser compreendida de acordo com o seu estilo.

No livro é exposto uma das tipologias utilizadas por alguns Gestalt-terapeutas, o eneagrama, abordagem que descreve tipos de personalidade. Atualmente uma das tipologias mais usadas é o DSM. Diante desta realidade, o autor defende a ideia de que a compreensão diagnóstica em psicoterapia tem como objetivo obter o padrão para ajudar o cliente a flexibilizá-lo, descristalizando-o e reduzindo-o ao mínimo indispensável para que tenha acesso mais franco a seus recursos criativos, sem, entretanto, rotulá-lo. Para que esta postura adotada na psicoterapia seja compreendida por outros profissionais, o autor apresenta uma correlação entre o Ciclo do Contato e o DSM.

O capítulo 3 explicita inicialmente o Ciclo do Contato, conceito essencial para estabelecer a relação com DSM, como proposto no capítulo anterior. Assim a perspectiva do Ciclo do Contato surge como instrumento importante, à serviço da relação dialógica, utilizado para compreensão diagnóstica, em seu fundamento, estrutura bem como no processo em que se configura o sofrimento, por vezes, denunciado pelo cliente.

O autor apresente o Ciclo do Contato composto por oito etapas, a saber: sensação, conscientização, mobilização, ação, interação, contato final, fechamento e retirada. Além da originalidade na quantidade das etapas, existe também alteração do termo "bloqueios de contato" para "descontinuação", uma vez que acredita que o contato não deixa de existir e, portanto, não fica bloqueado. Na "descontinuação", as fases afirmadas pelo autor são: dessensibilização, deflexão, introjeção, projeção, proflexão, retroflexão, egotismo e confluência.

Nota-se que o mesmo não considera a etapa da fluidez / fixação, e isto é decorrente ao fato de que para ele o ser vivo está sempre aberto ao contato, mesmo quando sua fluidez está muito reduzida. Ainda nesta linha de pensamento, o capítulo apresenta que é preciso compreender o indivíduo a partir de sua própria experiência, ou seja, da sua forma de se relacionar consigo e com o outro.

Assim, a "descontinuação" descrita no ciclo de contato como base para uma forma predominante de ser, um estilo de personalidade, sem deixar de considerá-lo como um ato, momentâneo; um estado, uma alternativa ao estilo de personalidade; uma estrutura, ou estilo de personalidade, ou seja, uma forma de organização e de ação, um jeito de estar no mundo. Por isso quando um psicoterapeuta busca compreender a personalidade do cliente, o foco não está em determinar uma classificação em patologias ou transtornos, mas sem em compreender como é a forma, o estilo e as relações predominante de forma de contato. Em sendo a estrutura da personalidade algo plástico, flexível, em constante reorganização e atualização, com elementos novos e antigos, o que permite diferentes mudanças ao longo da vida, é sugerido pelo autor que o psicoterapeuta vise antes à saúde, que a doença. Isto pois, assevera que o que precisa ser modificado é o que porventura haja de cristalizado, e não o estilo particular de cada ser.

O capítulo 4 traz mais informações sobre a relação entre o ciclo do contato e o DSM, onde a finalidade é apresentar as descontinuações e suas similaridades no DSM. Para cumprir com seu intento, ao descrever cada estilo de personalidade, o autor apresenta em qual etapa do ciclo está manifestado a descontinuação e ainda expõe suas características mais marcantes em relação à cognição, sexualidade, linguagem, emoção, divindade, vocações profissionais, socialização, sabedoria e adesão à terapia. Além de possibilitar conhecer cada forma de manifestação, apresentam-se ainda as principais condutas profissionais a cada estilo de personalidade.

Seguindo em direção ao final do livro, o Capítulo 5, conclui-se que é possível ampliar o diálogo entre psiquiatras e psicólogos por meio da Gestalt-terapia e do DSM, sempre evidenciando a importância de compreender o ser humano para além de uma possível patologia, como uma totalidade de sentido. É importante ressaltar que na visão da Gestalt-terapia, quando se diz em compreensão diagnóstica, não se tem como objetivo identificar doenças, mas sim compreender a forma de viver e relacionar do cliente, para que assim, o trabalho terapêutico, consiga apontar possíveis prognósticos.

Encerro esta resenha agradecendo a oportunidade de ter contato com uma obra tão rara, moderna e importante no campo das profissões da saúde. Recomendo a leitura do livro, por considerar que o mesmo está composto de informações relevantes, atuais e principalmente sobre um tema de grande valia na atualidade.

Maria Paula Miranda Chaim - Graduanda em Psicologia, $10^{\circ}$ período, na Pontifícia Universidade Católica de Goiás. E-mail:mpchaim@gmail.com

Danilo Suassuna Martins Costa - Doutorando e Mestre em Psicologia pela Pontifícia Universidade Católica de Goiás (2008), possui graduação em Psicologia pela mesma instituição. Especialização em Pós-Graduação em Psicologia Clínica pelo Instituto de Instituto de Treinamento e Pesquisa em Gestalt Terapia de Goiânia. E-mail: danilo@institutosuassuna.com

Recebido em 30.08.2015 Aceito em 12.12.2015 